\title{
Trielectrode Plasma Reactor for Water Treatment
}

L. Giuliani, ${ }^{1,2}$ L. De Angelis, ${ }^{3}$ G. Diaz Bukvic, ${ }^{3}$ M. Zanini, ${ }^{1,2}$ F. Minotti, ${ }^{1,2}$ M. I. Errea, ${ }^{3}$ and D. Grondona ${ }^{1,2}$, a)

1) Universidad de Buenos Aires, Facultad de Ciencias Exactas y Naturales, Departamento de Física, Buenos Aires, Argentina. C1428EGA

${ }^{2)}$ CONICET-Universidad de Buenos Aires, Instituto de Física del Plasma (INFIP), Buenos Aires, Argentina. C1428EGA

3) Instituto Tecnológico de Buenos Aires (ITBA), Buenos Aires, Argentina. C1106ACD

(Dated: 21 May 2020)

Water pollution due to emerging organic pollutants, such as agrochemicals, has become a topic of growing interest worldwide. The increase of pollutants in aquatic systems stimulated the development of new strategies for water remediation. Plasma technology is an advanced oxidation process which has proved to be an efficient method for organic matter degradation. In this work, a novel design of a trielectrode plasma reactor based on a dielectric barrier discharge extended to a third electrode operated in ambient air is presented. The water to be treated flows through a gutter with low impedance and far from the electrodes connected to the voltage sources. The reactor operates in ambient air; it does not rely on the use of expensive inert gases. The design of the reactor is easily scalable. The performance of the reactor, in terms of the removal efficiency and the energy yield, was tested in an aqueous solution of the herbicide 2,4-dichlorophenoxyacetic acid (2,4-D), one of the most widely used around the world. The reactor presents a good efficiency in the removal of the herbicide 2,4-D and values of energy yield of about $240 \mathrm{mg} / \mathrm{kWh}$.

\section{INTRODUCTION}

Nowadays, the decrease in water quality due to emerging organic pollutants, such as agrochemicals, pharmaceutical and personal care products, disinfection by-products, gasoline additives, among others, has become a topic of growing interest worldwide. The increase in the type and concentration of pollutants in aquatic systems stimulated the development of new strategies for water remediation. Among them, the non-thermal plasma is an environmentally friendly technology; it has a low operational temperature, no need for addition of chemicals, and a high efficiency in the removal of different types of water pollutants ${ }^{1,2}$. In non-thermal plasma technology, reactive species such as $\mathrm{O}^{\bullet}, \mathrm{OH}^{\bullet}, \mathrm{O}_{3}$ and also UV radiation are generated, combining the contribution of active species and physical conditions that have shown to have a high efficiency in the degradation of many organic compounds as well as in the destruction and inactivation of viruses and bacteria $^{3}$. The non-thermal plasma is produced by high voltage (of a few $\mathrm{kV}$ ) electric discharges, like dielectric barrier discharges (DBD) ${ }^{4}$ or corona discharges 5 , generated in water or in a gas at atmospheric pressure, like ambient air, over water. There are a large number of reactors with different geometries for the treatment of different types of pollutants in water. In some reactors the electric discharges are generated between electrodes immersed in the water, mainly with a pointed electrode, needle type, powered by high voltage pulses. Also, gases like air or argon can circulate through the immersed pointed electrode, obtaining a gas-phase discharge within the water. In other reactor configurations, the electric discharge is generated in the air over the water and the discharge products are transferred to the water ${ }^{6-12}$.

In this work, a novel configuration for a plasma reactor based on a DBD extended to a third electrode is presented.

a)Electronic mail: grondona@df.uba.ar

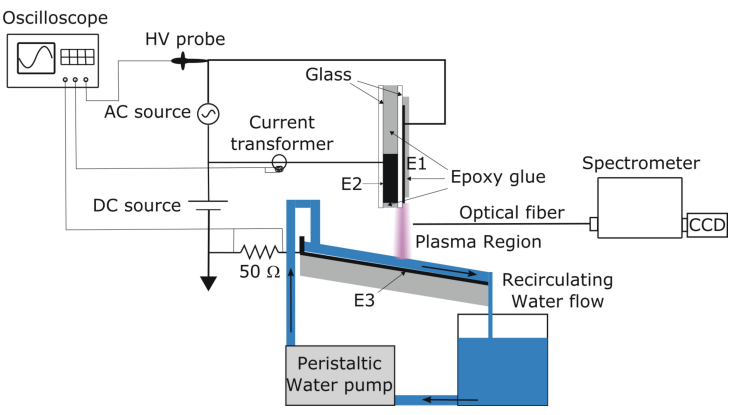

FIG. 1. Plasma reactor

The effectiveness of the reactor, in terms of the removal efficiency and the energy yield, was investigated in an aqueous solution of the herbicide 2,4-dichlorophenoxyacetic acid (2,4-D), one of the most widely used around the world; it was categorized by the United States Environmental Protection Agency (U.S. EPA) as a highly persistent chemical in aquatic and terrestrial environments ${ }^{13}$.

\section{EXPERIMENTAL SETUP}

\section{A. Reactor description}

A schematic of the trielectrode reactor used for water treatment is shown in Fig.(1).

A dielectric barrier discharge is generated by applying an AC high voltage $\left(V_{A C}\right)$ between two electrodes $\left(E_{1}\right.$ and $\left.E_{2}\right)$ separated by a $1 \mathrm{~mm}$ thick glass. Electrode $E_{1}$ is a $20 \mathrm{~mm}$ x $20 \mathrm{~mm}$ stainless steel sheet $0.5 \mathrm{~mm}$ thick. Electrode $E_{2}$ consists in a copper rod of $10 \mathrm{~mm} \times 3 \mathrm{~mm}$ rectangular cross section, and $80 \mathrm{~mm}$ length. Both electrodes are covered with epoxy glue except the lower edge of $E_{1}$. A third electrode 


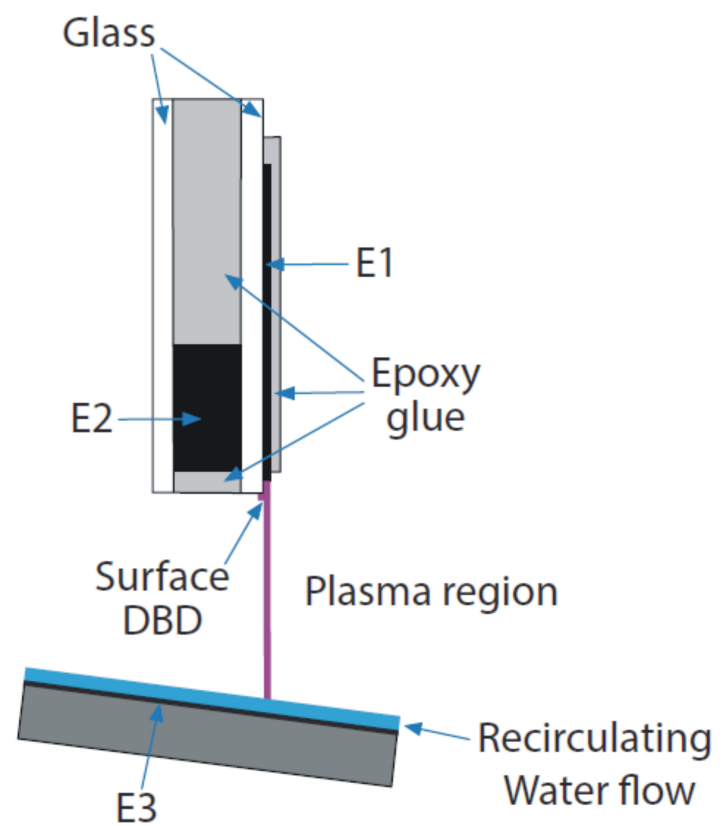

FIG. 2. Detailed scheme of the electrodes.

$\left(E_{3}\right)$, connected to ground, consists in an aluminium adhesive tape attached to a $40 \mathrm{~mm}$ wide gutter over which flows the water to be treated. The gap between the DBD electrodes and $E_{3}$ is $18 \mathrm{~mm}$. In Fig. (2) a detailed scheme of the electrode is shown.

The reactor operates in ambient air and the electrode system arrangement is enclosed within acrylic plates with only a small rectangular opening for the gutter to pass through. The surface DBD developed between $E_{1}$ and $E_{2}$ electrodes operates in the filamentary regime with formation of short-lived streamers ${ }^{14}$. These streamers are thin channels of non-thermal plasma with a self-propagating ionization front called head, which has a high and very localized electric field, depending very little on the external field ${ }^{15}$. When the discharge is on, the gap between the DBD electrodes and $E_{3}$ is crossed by long non-thermal plasma filaments resulting from the propagation of cathode directed streamers generated in the DBD to the third electrode ${ }^{16}$. In Fig.(3) photographs with different views of the reactor are shown, with the positions of the electrodes indicated. The streamers can propagate stably long distances along the gap to the third electrode only in the presence of an external electric field with a unique minimum electric field value $^{15}$. The external electric field necessary to extend the DBD plasma is generated by a DC high voltage source $\left(V_{D C}\right)$ that raises the voltage of the DBD electrodes with respect to the grounded electrode $E_{3}$.

The AC source consists in a function generator (Instek GFG-8216A), its signal is amplified by an audio amplifier (SKP MaxG-1400, 700W) and coupled to a high voltage transformer. The frequency of $V_{A C}$ is $10.5 \mathrm{kHz}$, which is the optimal matching frequency, established by the resonance between the transformer inductance and the capacity of the
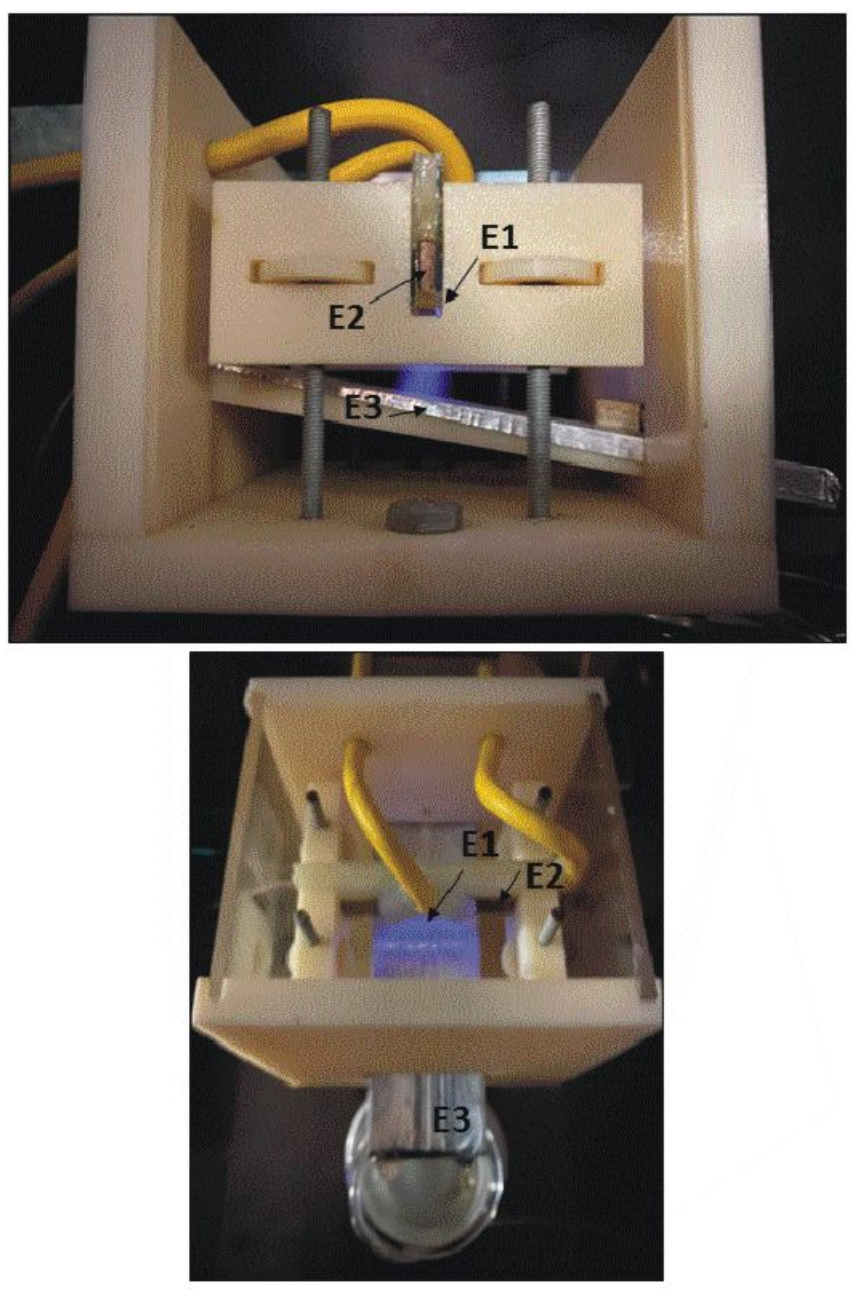

FIG. 3. Photographs of the plasma reactor.

electrodes. The amplitude of $V_{A C}$ is $5.5 \mathrm{kV}$. This value corresponds to the maximum value in which the reactor can be operated without sparking. The DC source (Brandenburg 797) was fixed at a working voltage of $V_{D C}=10 \mathrm{kV}$. The voltage of electrode $E_{1}(V)$, corresponding to $V_{A C}$ plus $V_{D C}$, was measured using a high voltage probe (Tektronix P6015A, 1000X $3.0 \mathrm{pF} 100 \mathrm{M} \Omega)$. The DBD current $\left(I_{D B D}\right)$ collected by electrode $E_{2}$ was measured with a current transformer (Bergoz CT-D5.0) and the current (I) collected by electrode $E_{3}$ was obtained from the voltage drop across a $50 \Omega$ resistor. The electrical signals were acquired with a four channel digital oscilloscope (Tektronix TDS2004B, 60MHz 1GS/s). Optical emission spectroscopy of the discharge was performed in the range $310-420 \mathrm{~nm}$ with a resolution of $0.029 \mathrm{~nm}$ using a spectrometer Horiba iHR 320 (2400 grooves $/ \mathrm{mm}$ ) coupled to a CCD detector (Synapse, model 354308). The light was collected from the plasma in the region between the DBD electrodes and the water surface and carried through a UV visible optical fiber to the entrance slit of the spectrometer. 


\section{B. Chemicals and analytical procedures}

Experiments were carried out over $70 \mathrm{ml}$ of 2,4-D solutions. 2,4-D was purchased from Sigma-Aldrich (purity $>$ 99\%). Chemicals were purchased and used without further purification: acetic acid (99.1\% , Merck), acetonitrile (HPLC grade, J.T. Backer) and $\mathrm{H}_{2} \mathrm{SO}_{4}(98 \%$, Merck). All solutions were prepared with Milli-Q water (resistivity > $18 \mathrm{M} \Omega$ ).

According to pesticides concentrations that could be found in industrial effluents from agricultural and manufacturing industries, the initial concentration was set at $10 \mathrm{mg} \mathrm{l}^{-1}$. The concentration of 2,4-D in the aqueous solutions were determined by high performance liquid chromatography (HPLC), using a HP 1100 Series apparatus with a Zorbax Eclipse XDB$\mathrm{C} 18$ column $(4.6 \mathrm{~mm} \times 250 \mathrm{~mm}, 5 \mu \mathrm{m})$, at $25^{\circ} \mathrm{C}$ and coupled to an Agilent Technologies $1200 \mathrm{UV}$-Vis detector, working at $\lambda=280 \mathrm{~nm}$. As mobile phase $55 \%$ acetonitrile, $30 \%$ acetic acid at $30 \%$ and $15 \%$ Milli-Q water solution was used, at 0.8 $\mathrm{ml} \mathrm{min}{ }^{-1}$ (retention time $(\mathrm{tr})=4.7 \mathrm{~min}$ ). After filtering the samples through $0.45 \mu \mathrm{m} \mathrm{PVdF}$ (Polyvinylidene fluoride) filters, $20 \mu \mathrm{l}$ of solution was injected in the HPLC.

The herbicide solution was recirculated in the reactor at a flow of $70 \mathrm{ml} / \mathrm{min}$ for 30, 60, 90, 120 and 180 minutes, and collected afterwards. Before each treatment, the device was washed with distilled water to remove possible remains of the previous solution. All the experiments were performed at room temperature. Also, each experiment was repeated two times and the accuracy of the concentration measurement was around $5 \%$.

\section{RESULTS AND DISCUSSION}

\section{A. Electrical signals}

Typical electrical signals of $V, I_{D B D}$ and $I$ are shown in Fig. (4). The voltage of electrode $E_{1}$ corresponds to a $V_{A C}$ signal with peak to peak amplitude of $11 \mathrm{kV}$ and a frequency of 10.5 $\mathrm{kHz}$ with a continuous component $V_{D C}$ of $10 \mathrm{kV}$. Once air breakdown occurs, the conduction current consists in streamers between the DBD electrodes, and in streamers crossing the electrode gap. This is appreciated in the appearance of the series of pulses superimposed on the capacitive current. These conduction pulses reach values of $\sim 10 \mathrm{~mA}$ and $\sim 60 \mathrm{~mA}$ for $I_{D B D}$ and $I$, respectively. The onset of the streamers crossing the gap occurs at a $V$ value about $12 \mathrm{kV}$, corresponding to a $V_{A C}$ amplitude of $2 \mathrm{kV}$, and the extinction takes place, approximately, at the maximum value of $V, V_{A C}$ amplitude $5.5 \mathrm{kV}$.

\section{B. External electric field}

As mentioned above, to extend the plasma region an external electric field is necessary for the propagation to the third electrode of the streamers generated at the DBD. The minimum external electric field that is required to sustain the steady growth and propagation of a streamer in air is between $4 \mathrm{kV} / \mathrm{cm}$ and $5 \mathrm{kV} / \mathrm{cm}^{15}$. At the start of the DBD discharge the

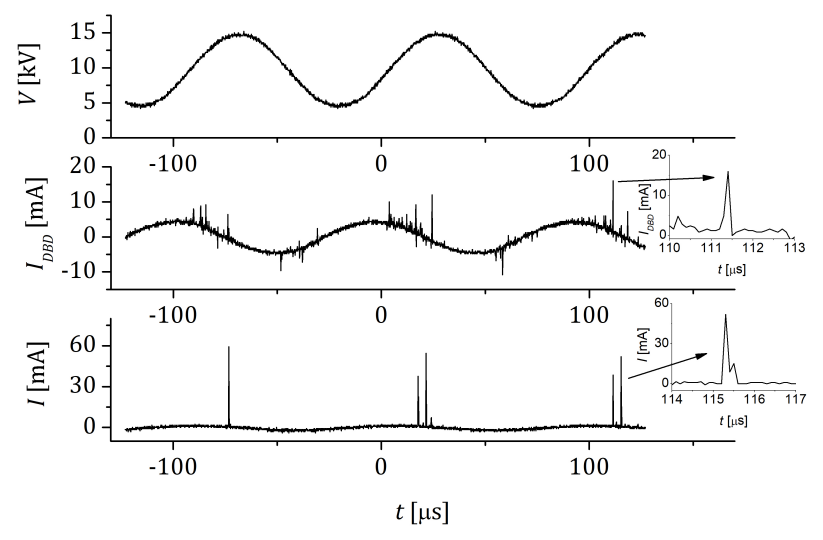

FIG. 4. Signals of: voltage of electrode $E_{1}(V)$, DBD current $\left(I_{D B D}\right)$ and current collected by electrode $E_{3}(I)$. The insets in both current signals show a magnified view of the current peaks, of about $400 \mathrm{~ns}$ width

electric field is well described by the laplacian electric field, but once the discharge is ignited, the charges accumulated on the dielectric plate reduce the electric field in the locality of the DBD electrodes, up to the point of interrupting the discharge when the magnitude of $V_{A C}$ starts decreasing.

In order to evaluate the external electric field in the gap, the field generated by a metallic strip of width $w$ at some distance from the surface of a plane dielectric with electric permittivity $\varepsilon_{d}$ and width $h$, lying over a conducting plane at zero potential was considered (see Fig. (5)). The coordinate $z$ was taken normal to the surface of the dielectric, with origin at this surface. The lower edge of the strip runs parallel to the surface of the dielectric. The coordinate along this direction was denoted as $y$, and as $x$ the coordinate orthogonal to $y$ and $z$. The model assumes no dependence of the field on the $y$ coordinate. The plane strip is tilted an angle $\alpha$ relative to the vertical axis $z$, so that in order to identify a given position on the strip was taken, in addition to the coordinate $y$, a coordinate $\xi$ normal to $y$ in the plane of the strip, with origin on the lower edge of the strip. Besides, this lower edge was considered to be at a generic position denoted by $x_{0}$ and $z_{0}$. Denoting the charge surface density in the strip as $\sigma(\xi)$, a section of the strip of infinitesimal width $d \xi$ at position $\xi$ has thus a charge per unit length of value $\sigma(\xi) d \xi$. The electric potential generated by this element, equivalent to a charged wire, in the region above the dielectric can be readily evaluated by the method of images ${ }^{17}$ to be

$$
\begin{aligned}
d V(x, z)=\frac{\sigma(\xi) d \xi}{4 \pi \varepsilon_{0}}\left\{\operatorname { l n } \left[\left(x_{0}-\xi \sin \alpha-x\right)^{2}\right.\right. \\
\left.+\left(z_{0}+\xi \cos \alpha-z\right)^{2}\right] \\
+\sum_{k=0}^{\infty} C_{2 k+1} \ln \left[\left(x_{0}-\xi \sin \alpha-x\right)^{2}\right. \\
\left.\left.+\left(2 k h+z_{0}+\xi \cos \alpha+z\right)^{2}\right]\right\},
\end{aligned}
$$

where the coefficients in the summation are given recursively 

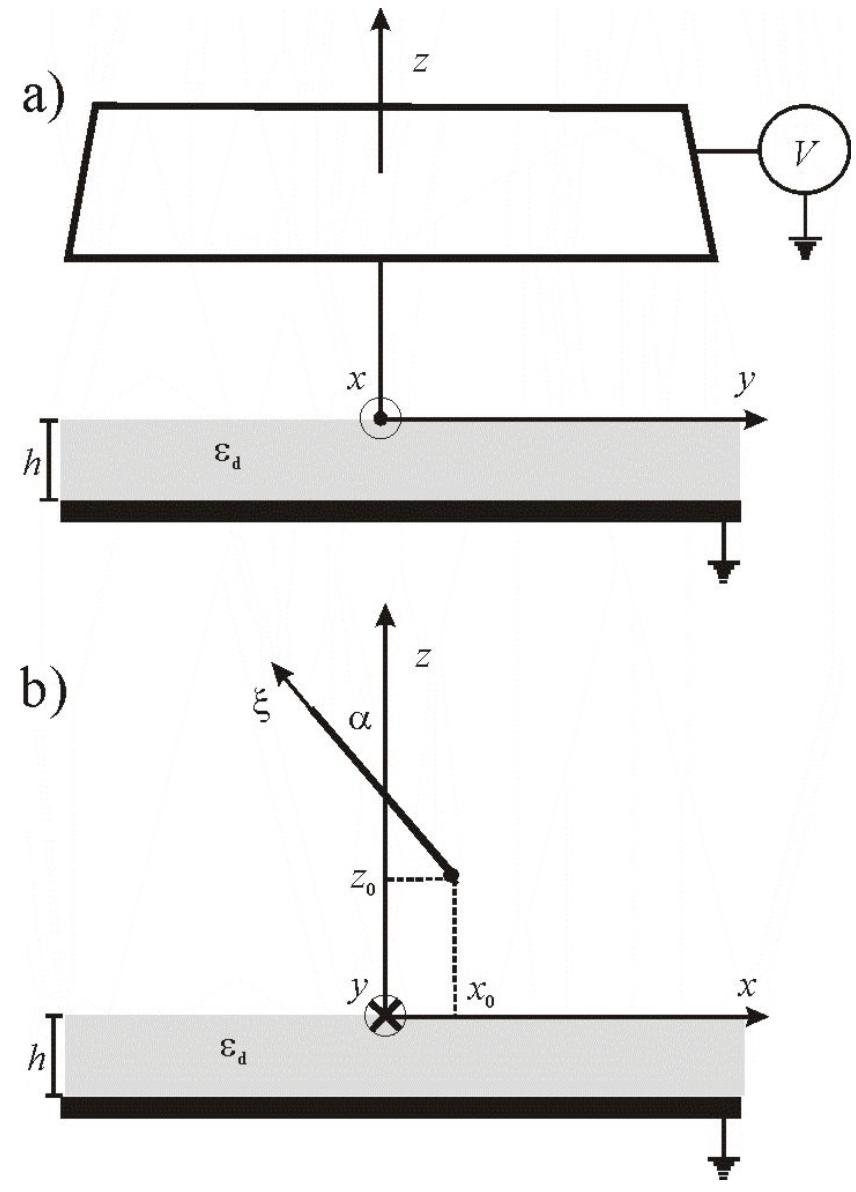

FIG. 5. Sketch showing the configuration and notation considered for the evaluation of the electric field in the region between the DBD electrodes and the water surface: a) front view, b) side view.

by the expressions

$$
\begin{aligned}
C_{1} & =\frac{\varepsilon_{0}-\varepsilon_{d}}{\varepsilon_{0}+\varepsilon_{d}}, \\
C_{2} & =\frac{2 \varepsilon_{d}}{\varepsilon_{0}+\varepsilon_{d}}, \\
C_{2 k+1} & =-\frac{2 \varepsilon_{0}}{\varepsilon_{0}+\varepsilon_{d}} C_{2 k}, \text { for } k>0, \\
C_{2 k} & =\frac{\varepsilon_{0}-\varepsilon_{d}}{\varepsilon_{0}+\varepsilon_{d}} C_{2 k-2}, \text { for } k>1 .
\end{aligned}
$$

In order to model the charge distribution on a metallic strip, the conformal mapping technique ${ }^{18}$ was used to relate the simple analytical solution of the electric potential of an infinite metallic cylinder of radius $w / 4$ to that of an infinite strip of width $w$, to finally obtain $\sigma$ as proportional to the electric field at the strip surface:

$$
\sigma(\xi)=\frac{K}{\sqrt{1-(2 \xi-w)^{2} / w^{2}}},
$$

where $K$ is a constant to be determined.

In the application to the reactor configuration, the electric field is due to the superposition of the two electrodes of the

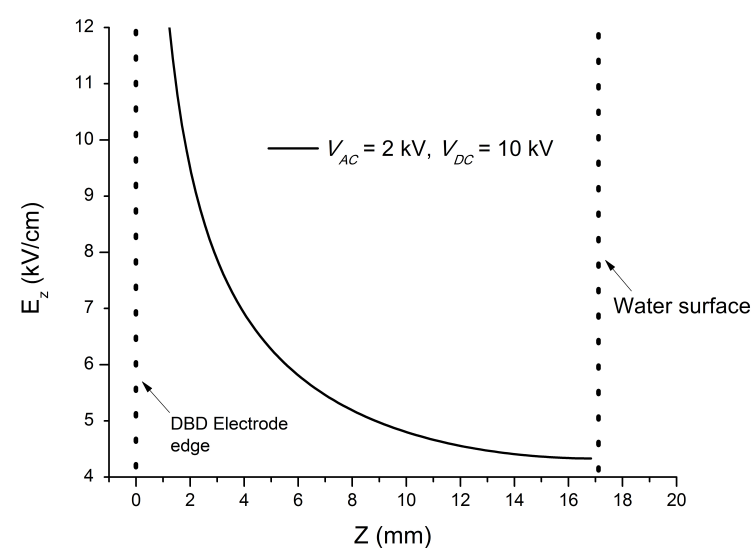

FIG. 6. Electric field at the onset of the streamer propagation for all $\mathrm{z}$ positions in the electrode gap.

DBD. As a reasonable approximation the electrode $E_{1}$ was modeled as a strip, and since the field away from electrode $E_{2}$ is the most relevant, only its inner surface (that closest to $E_{1}$ ) was considered, and thus modeled as a strip as well. In this way, the contribution of each electrode to the potential is given by expressions 1 and 2 with appropriate values of $x_{0}$, $z_{0}, K$ and $w$. Using subscripts 1 and 2 for the corresponding parameters of the electrodes $E_{1}$ and $E_{2}$, and denoting as $d \widetilde{V}$ the expression 1 in which the function $\sigma$ used is that given by 2 with $K=1$, the system of equations corresponding to the potential evaluated at the positions of the electrodes can be written as

$$
\begin{aligned}
V_{1}= & K_{1} \int_{\xi=0}^{\xi=w_{1}} d \widetilde{V}_{1}\left(x_{01}, z_{01}\right) \\
& +K_{2} \int_{\xi=0}^{\xi=w_{2}} d \widetilde{V}_{2}\left(x_{01}, z_{01}\right), \\
V_{2}= & K_{1} \int_{\xi=0}^{\xi=w_{1}} d \widetilde{V}_{1}\left(x_{02}, z_{02}\right) \\
& +K_{2} \int_{\xi=0}^{\xi=w_{2}} d \widetilde{V}_{2}\left(x_{02}, z_{02}\right) .
\end{aligned}
$$

From system 3 the corresponding values of $K_{1,2}$ for given potentials of the electrodes $V_{1,2}$ can be obtained, where $V_{1}=$ $V_{A C}+V_{D C}$ and $V_{2}=V_{D C}$. In this way, the surface charge densities are fully determined, and the electric field at a given observation point $(x, z)$ is obtained by analytic derivation of expressions 1 for each electrode and further numerical integration on $\xi$.

Fig.(6) shows the external electric field $\left(E_{z}\right)$ in the region between the DBD electrodes and the water surface for the reactor operating voltages corresponding to the onset of the streamers crossing this gap $\left(V_{A C}=2 \mathrm{kV}\right.$ and $\left.V_{D C}=10 \mathrm{kV}\right)$. It can be seen that this electric field has values high enough to sustain the steady growth and propagation of a streamer in air in the whole gap, larger than $\sim 4 \mathrm{kV} / \mathrm{cm}^{15}$. It is worth noting that for $V_{A C}$ below $2 \mathrm{kV}$, although the DBD is on, there are no 


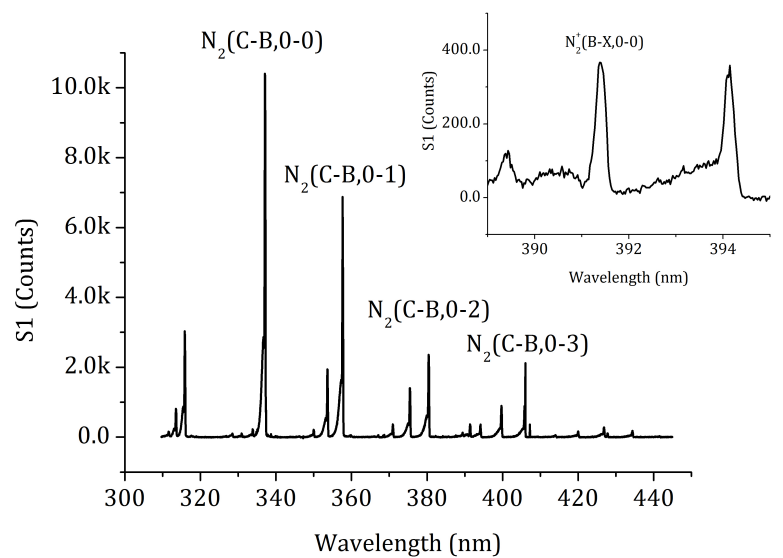

FIG. 7. Optical emission spectrum in the range $310-420 \mathrm{~nm}$ of the plasma across the gap.

streamers crossing the gap to the water surface.

\section{Optical emission spectroscopy}

Fig.(7) shows an optical emission spectrum in the range $310-420 \mathrm{~nm}$ of the plasma across the gap.

The detected light comes from the streamer head where the electron density and temperature are high enough to produce intense vibrational excitation and ionization of the molecules ${ }^{19}$.

In this spectrum the different vibrational bands of neutral nitrogen molecules $\mathrm{N}_{2}(\mathrm{C}-\mathrm{B})$ and of molecular ions $\mathrm{N}_{2}^{+}(\mathrm{B}-\mathrm{X})$ can be observed.

Assuming that in air at atmospheric pressure, the excitation process only comes from direct electron impact, from the local continuity equations for the excitation by direct electron impact and their successive collisional quenching in a steadystate approximation, it is possible to evaluate the reduced electric field at the streamer head ${ }^{20,21}$

The local electric field of a self-propagating streamer head was determined from the ratio of the integrated intensity peaks of $\mathrm{N}_{2}^{+}(\mathrm{B}-\mathrm{X}, 0-0)$ emissions at $391.4 \mathrm{~nm}$ and $\mathrm{N}_{2}$ (C-B,0-0) emissions at $337.1 \mathrm{~nm}$. The ratio of the integrated intensity peaks resulted in a factor of $(2.8 \pm 0.1) 10^{-2}$, which corresponds to a reduced electric field at the streamer head of (670 $\pm 10)$ Td. Taking the air number density corresponding to atmospheric pressure and ambient temperature $\left(\mathrm{N}=2.4 \times 10^{25}\right.$ $\mathrm{m}^{-3}$ ), the resulting value for the head electric field is about $160 \mathrm{kV} \mathrm{cm}^{-1}$. Although this value could be slightly modified due to gas heating by the discharge, such a high value can be found under these experimental conditions only at the head of a streamer. This result shows that the discharge gap is crossed by long plasma filaments resulting from the propagation of cathode directed streamers generated in the DBD.

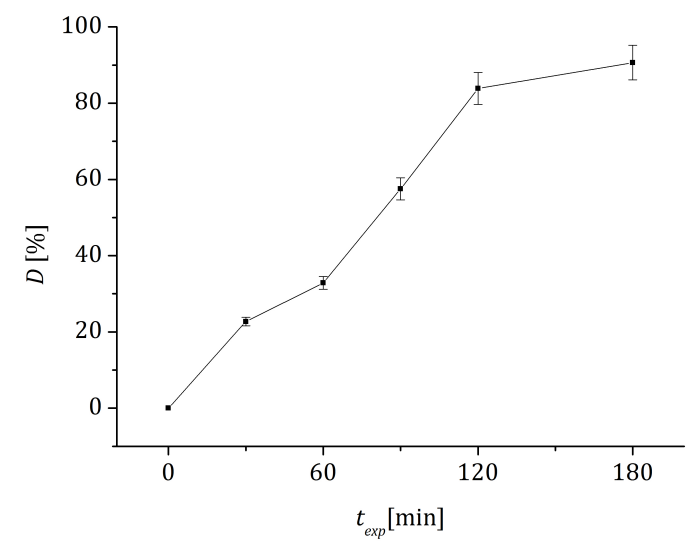

FIG. 8. Percent degradation as function of exposure time.

\section{Analytical procedure}

The efficiency of the reactor was evaluated by the degradation of the 2,4-D. The percent degradation $(D)$ is defined as:

$$
D=\left(1-\frac{C}{C_{0}}\right) \times 100
$$

where $C_{0}$ is the initial concentration of 2,4-D and $C$ the concentration after treatment, which is plotted in Fig.(8) against time of exposure $\left(t_{\text {exp }}\right)$. From Fig.(8), it can be noted that after three hour treatment, the degradation of 2,4-D is almost total.

Due to the reactor configuration having three electrodes, it is not possible to evaluate the time average active power dissipated in the plasma by the area bounded by the charge-voltage diagram (lissajous figure) as it is usually done in a two electrode DBD. Because of that, the average power $(P)$ was calculated from the instantaneous voltage and current waveforms as:

$$
P=\frac{1}{T} \int_{0}^{T}\left(V I+V_{A C} I_{D B D}\right) d t
$$

where $T$ is the period of $V_{A C}$. The result obtained as an average over ten electrical signals is $P=(1.1 \pm 0.1) \mathrm{W}$, of which about $0.8 \mathrm{~W}$ corresponds to the discharge in the gap, and $0.3 \mathrm{~W}$ to the DBD. From the electrical signal, it can be seen that the current pulses reach values up to several tens of $\mathrm{mA}$ an the applied voltage values are several $\mathrm{kV}$, but in a period of the current signal, when the discharge in on, only a few short pulses appear. For this reason, the effective power dissipated in the plasma is relatively low.

The energy yield $Y$ is defined as the ratio between the degraded mass of 2,4-D during plasma treatment and the energy spent as

$$
Y\left(\frac{\mathrm{mg}}{\mathrm{kWh}}\right)=\frac{\operatorname{Vol}(1) \times C_{0}\left(\frac{\mathrm{mg}}{1}\right) \times D / 100}{P(\mathrm{~kW}) \times t_{\exp }(\mathrm{h})}
$$




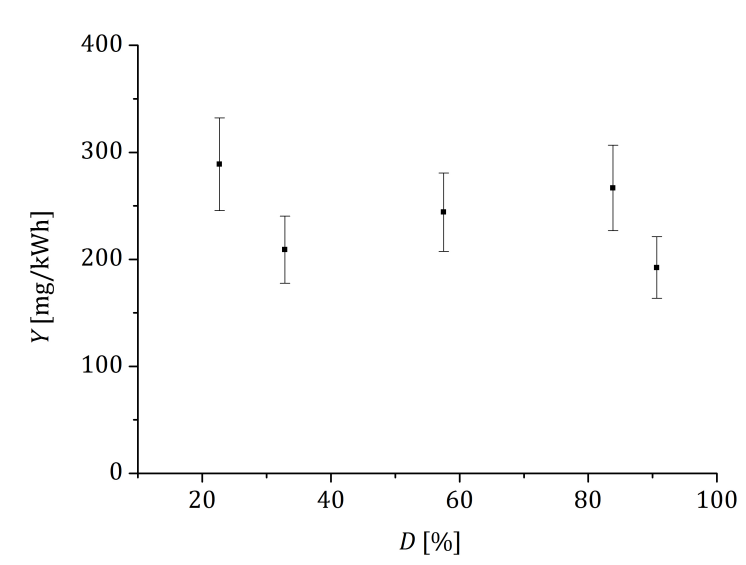

FIG. 9. Energy yield as function of the percent degradation.

where $\mathrm{Vol}=70 \mathrm{ml}$ is the treated volume.

In Fig.(9) the energy yield as a function of the D value is shown. It can be seen that the energy yield does not vary appreciably with $D$ and has a mean value of $(240 \pm 20) \mathrm{mg} / \mathrm{kWh}$.

\section{FINAL REMARKS}

A novel trielectrode plasma reactor for water treatment based on a dielectric barrier discharge extended to a third electrode operated in ambient air is presented. In this reactor the water to be treated flows through a gutter with low impedance and several centimeters far from the electrodes $\left(E_{1}\right.$ and $E_{2}$ ) connected to the voltage sources. The distance between DBD electrodes and the flowing water is not a critical parameter. The distance could be varied; the only condition is that the external electric field in the filamentary propagation direction must exceed the minimum electric field value needed for stable propagation of the streamers in ambient air across the gap. This reactor is easily scalable; it is possible to increase the volume of treated water by increasing the length of the DBD electrodes. Also, since it operates in ambient air, it does not rely on the use of expensive inert gases. The performance of the reactor, in terms of the removal efficiency and the energy yield, was tested in an aqueous solution of the herbicide 2,4-D. The reactor shows a good efficiency, comparable to the efficiency obtained with other advanced oxidation techniques, like Fenton process. The 2,4-D concentration after $3 \mathrm{~h}$ of treatment was $0.94 \mathrm{mg} / \mathrm{L}$, achieving a degradation efficiency of $90.7 \%$, comparable to those obtained with other advanced oxidation techniques, like Fenton process. At neutral values of $\mathrm{pH}$, up to $90 \%$ efficiency can be reached by Solar Photo-Fenton, requiring 6 hours of exposition. This means that in order to attain such efficiency values, the time demanded with Fenton doubles the one needed with the DBD reactor $^{22}$. Also, the non-thermal plasma technology is more environmentally friendly since addition of others chemical agents is not necessary. The energy yield is comparable to that obtained in other plasma reactors operated in ambient air for similar initial concentrations ${ }^{23}$.

\section{ACKNOWLEDGMENTS}

This work was financed by grants from CONICET: PUE $201822920180100050 \mathrm{CO}$ and PIP 2017-2019 $11220170100627 \mathrm{CO}$, AGENCIA - FONCYT PICT-20172869, and from the UNIVERSIDAD DE BUENOS AIRES UBACYT 2016 Mod I 20020150100096BA.

\section{AIP PUBLISHING DATA SHARING POLICY}

The data that support the findings of this study are available from the corresponding author upon reasonable request.

${ }^{1}$ J. Foster, Physics of Plasmas 24, 055501 (2017).

${ }^{2}$ K. Weltmann, J. Kolb, D. U. W. Holub, M. Šimek, K. Ostrikov, S. Hamaguchi, U. Cvelbar, M. Černák, B. Locke, A. F. P. Favia, and K. Becker, Plasma Processes and Polymers 19, 1 (2019).

${ }^{3}$ M. Magureanu, C. Bradu, and V. Parvulescu, J. Phys. D: Appl. Phys. 51, 313002 (2018).

${ }^{4}$ R. Brandenburg, Plasma Sources Sci. Technol. 26, 053001 (2017).

${ }^{5}$ J. Chang, P. Lawless, and T. Yamamoto, Transactions on Plasma Science 19, 1152 (1991)

${ }^{6}$ B. Jiang, J. Zheng, S. Qiu, M. Wu, Q. Zhang, Z. Yan, and Q. Xue, Chemical Engineering Journal 236, 348 (2014).

${ }^{7}$ K. Shimizu, S. Muramatsu, M. Sonoda, and T. Blajan, International Journal of Plasma Environmental Science \& Technology 4, 58 (2010).

${ }^{8}$ N. Wardenier, P. Vanraes, A. Nikiforov, S. V. Hulle, and C. Leys, Journal of Hazardous Materials 362, 238 (2019).

${ }^{9}$ G. Iervolino, V. Vaiano, and V. Palm, Separation and Purification Technology 215,155 (2019).

${ }^{10}$ R. K. Singh, L. Philip, and S. Ramanujam, Chemical Engineering Journal 355, 269 (2019)

${ }^{11}$ M. Hijosa-Valsero, R. Molina, H. Schikora, M. Mülle, and J. Bayona, Water Research 47, 1701 (2013).

${ }^{12}$ K. Aziz, M. Miessner, A. Mahyar, S. Mueller, D. Kalass, D. Moeller, and K. Omera, Separation and Purification Technology 216, 51 (2019).

${ }^{13}$ Update of Human Health Ambient Water Quality Criteria: 2,4 Dichlorophenol, US EPA, 120-83-2 Washington. DC, office of science and technology office of water u.s. environmental protection agency. ed. (2015).

${ }^{14}$ U. Kogelschatz, Plasma Chemistry and Plasma Processing 23, 1 (20o3).

${ }^{15}$ Y. Raizer, Gas Discharge Physics (New York: Springer, 1991).

${ }^{16} \mathrm{~J}$. L. Gallego, D. Grondona, and F. Minotti, Journal of Physics D: Applied Physics 47, 205202 (2014)

${ }^{17}$ J. Jackson, Classical Electrodynamics (John Wiley \& Sons, 1999)

${ }^{18}$ Z. Nehari, Conformal Mapping (Dover Publications, 1952).

${ }^{19}$ S. Pancheshnyi, M. Nudnova, and A. Starikovskii, Phys. Rev. E 71, 016407 (2005).

${ }^{20}$ V. Lago, D. Grondona, H. Kelly, R. Sosa, A. Marquez, and G. Artana IEEE Transactions on Dielectrics and Electrical Insulation 16, 292 (2009).

${ }^{21}$ S. M. Starikovskaia, K. Allegraud, O. Guaitella, and A. Rousseau, J. Phys. D: Appl. Phys. 43, 124007 (2010).

${ }^{22}$ A. Serra-Clusellas, L. D. Angelis, C. Lin, P. Vo, M. Bayati, L. Sumner, Z. Lei, N. Amaral, L. Bertini, J. Mazza, L. R. Pizzio, J. Stripeikis, J. Rengifo-Herrera, and M. F. de Cortalezzi, Water Research 144, 572 (2018).

${ }^{23}$ C. Bradu, Journal of Hazardous Materials 336, 42 (2017). 


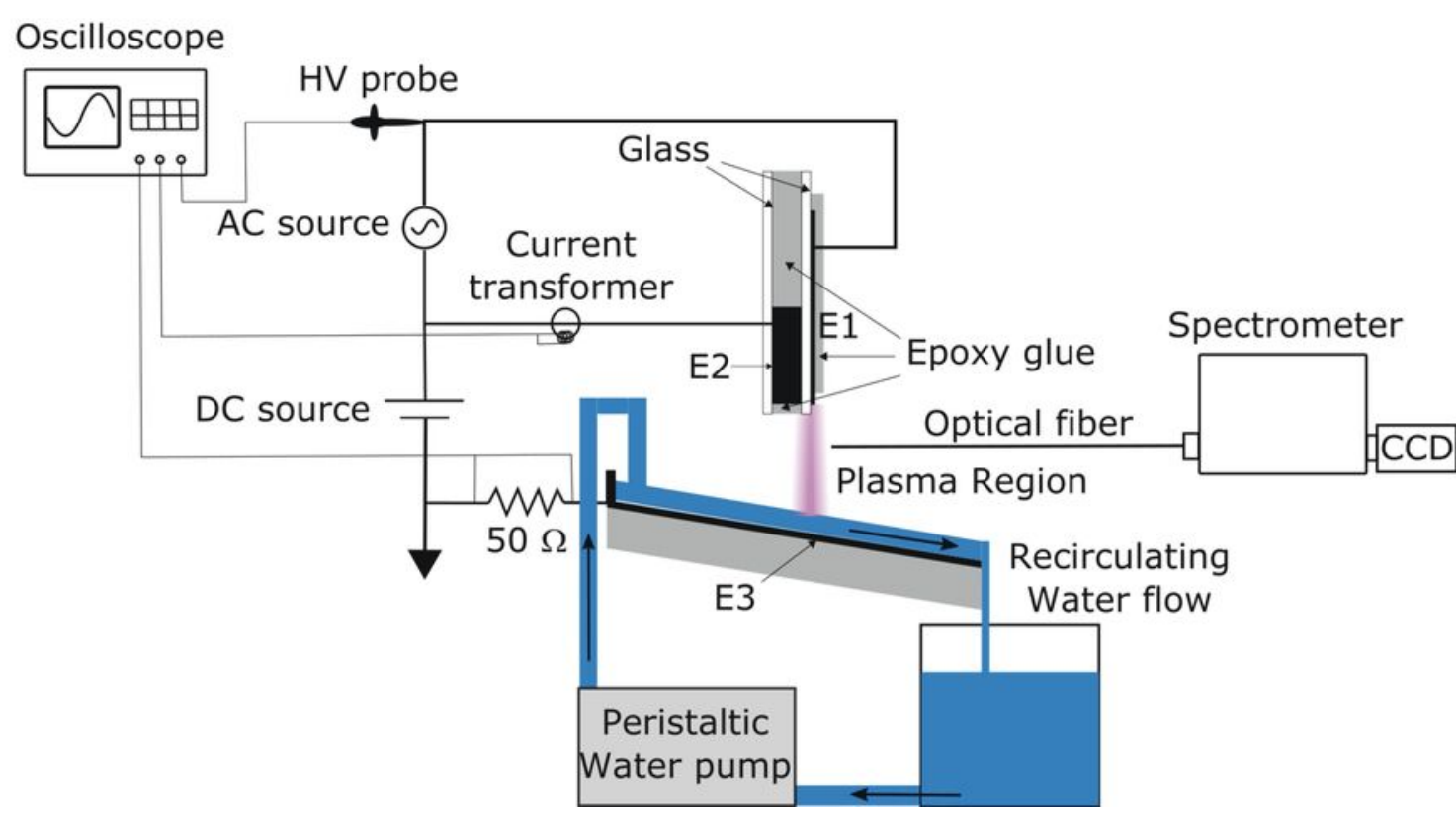




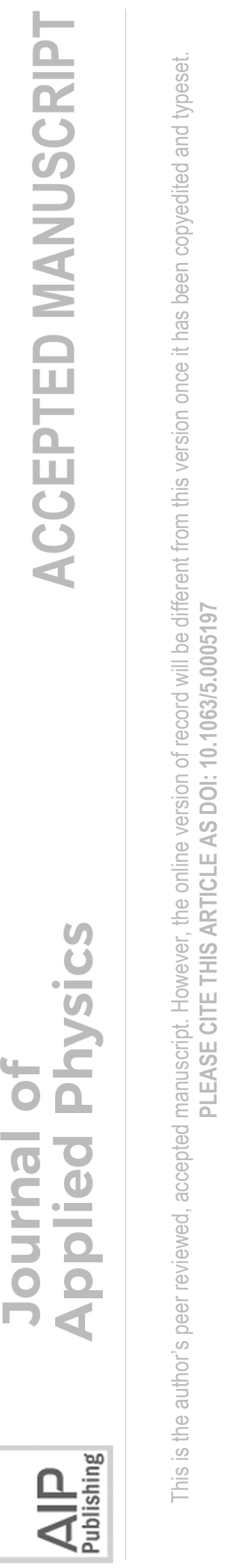

Glass
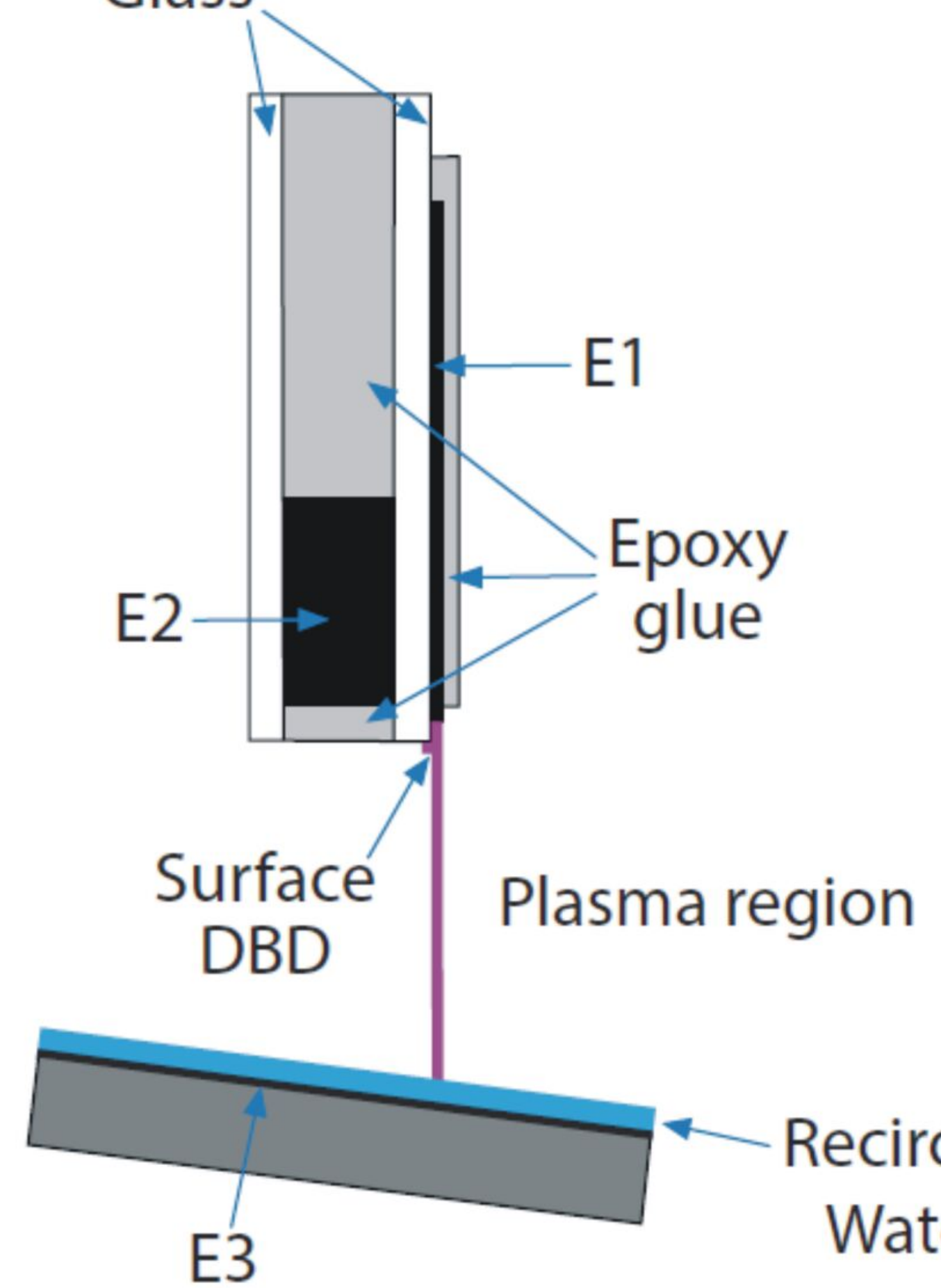

Recirculating Water flow 


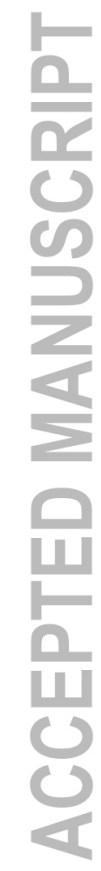

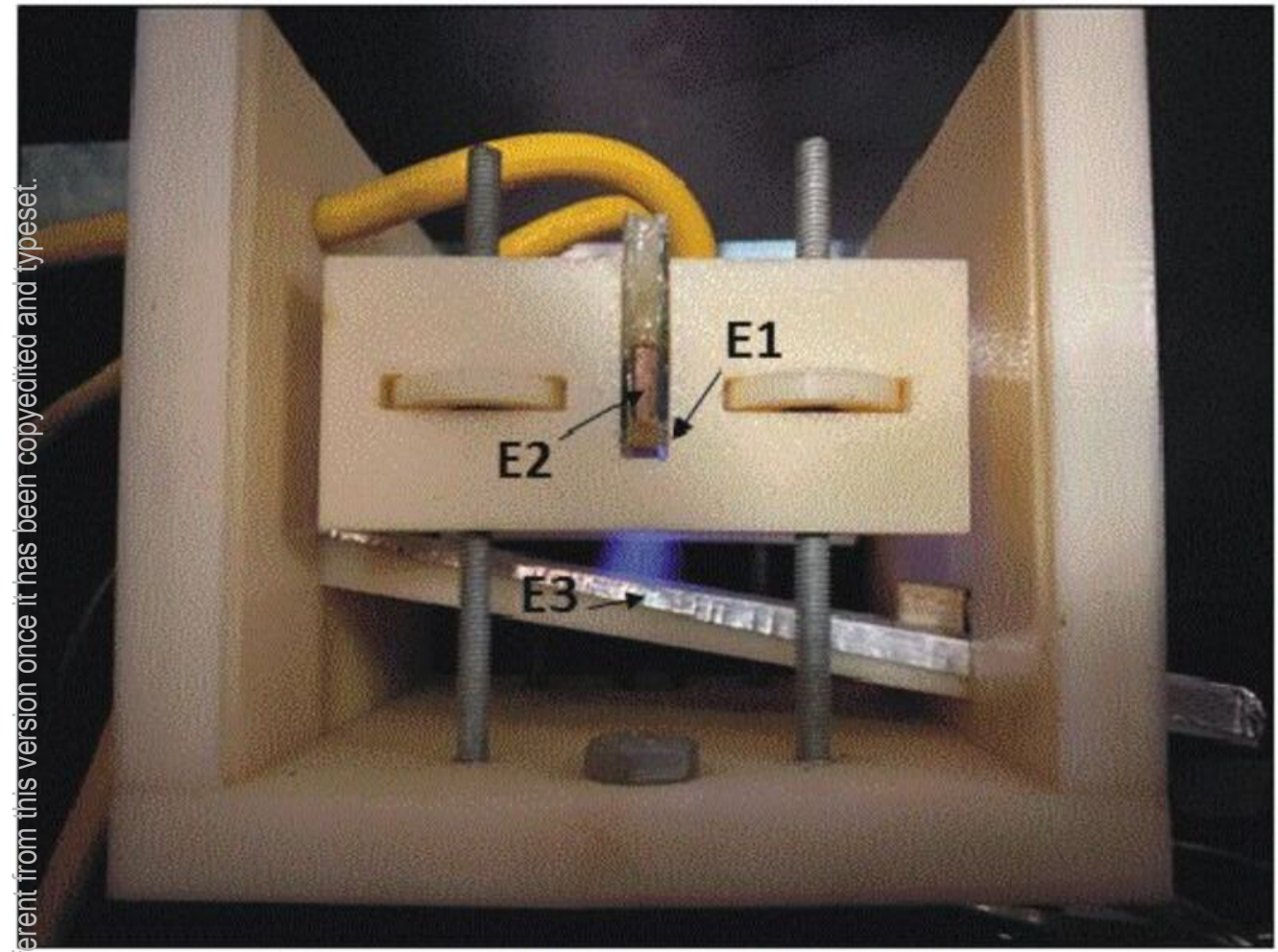

0
0
0

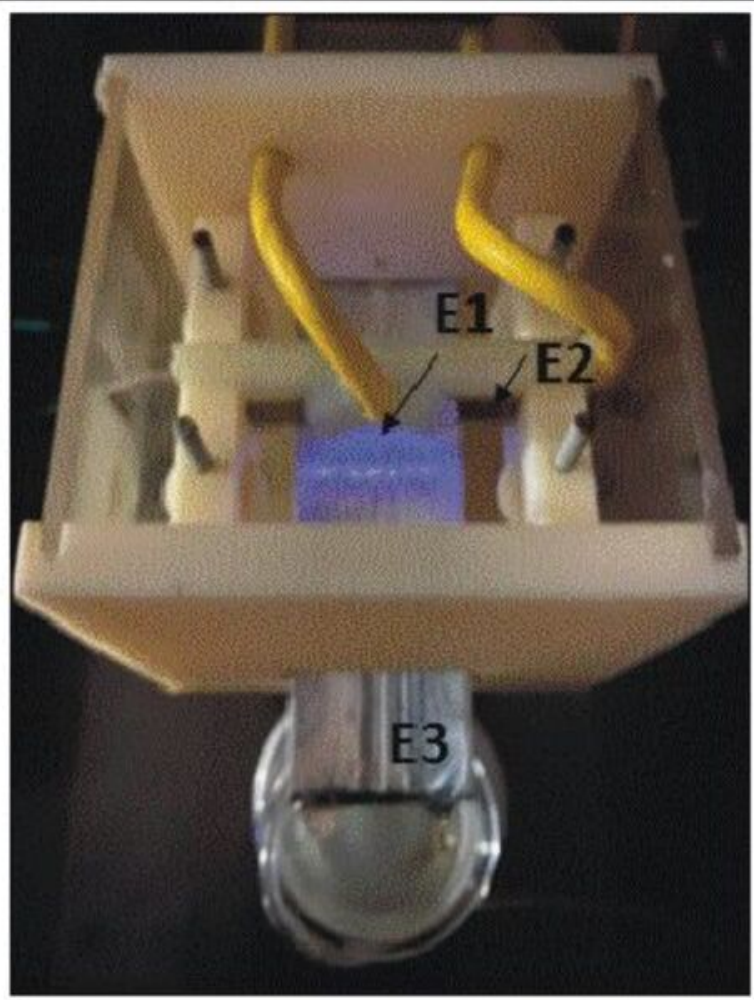

0
0
0

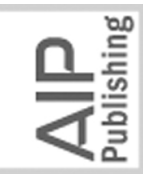




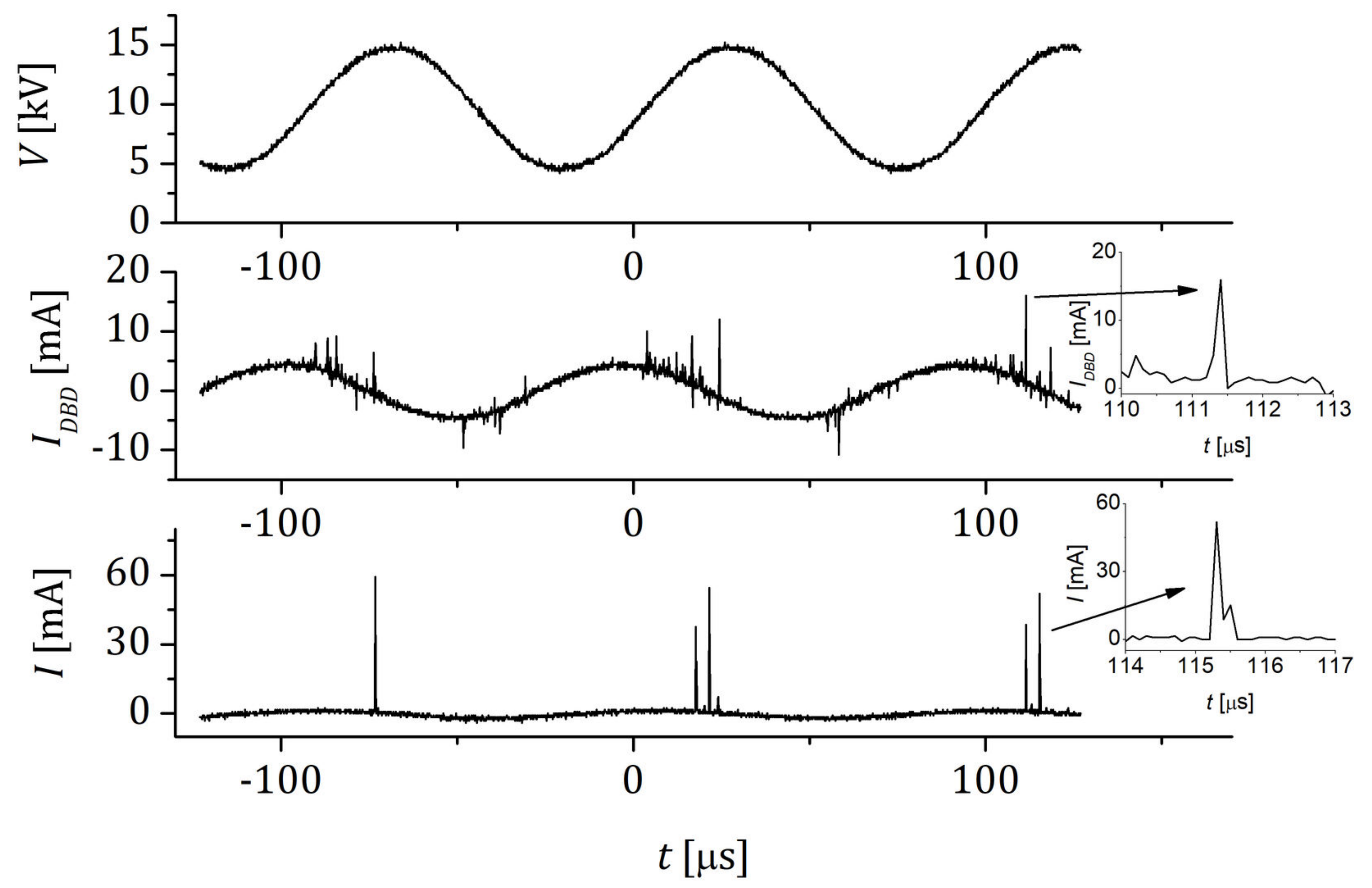




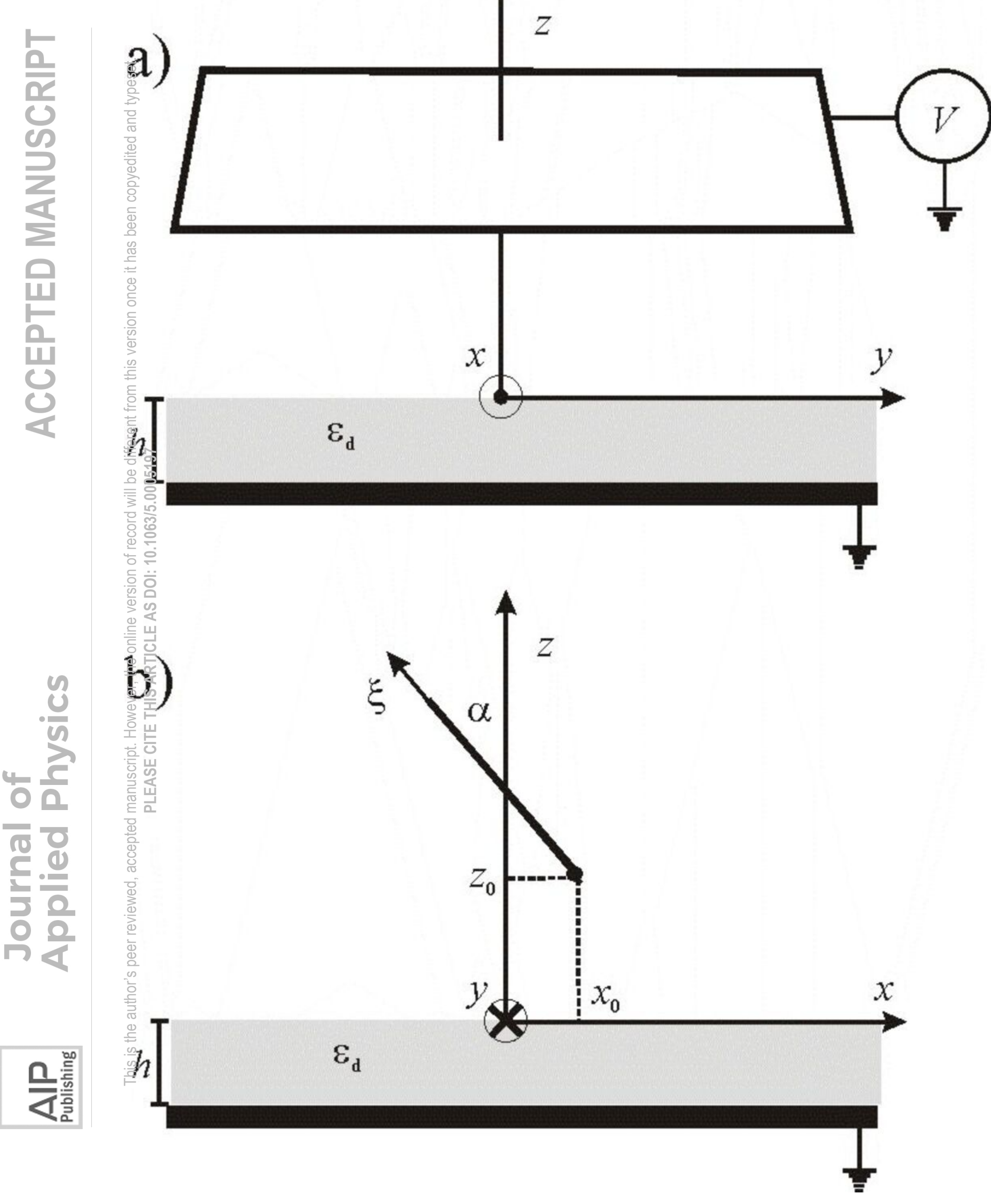




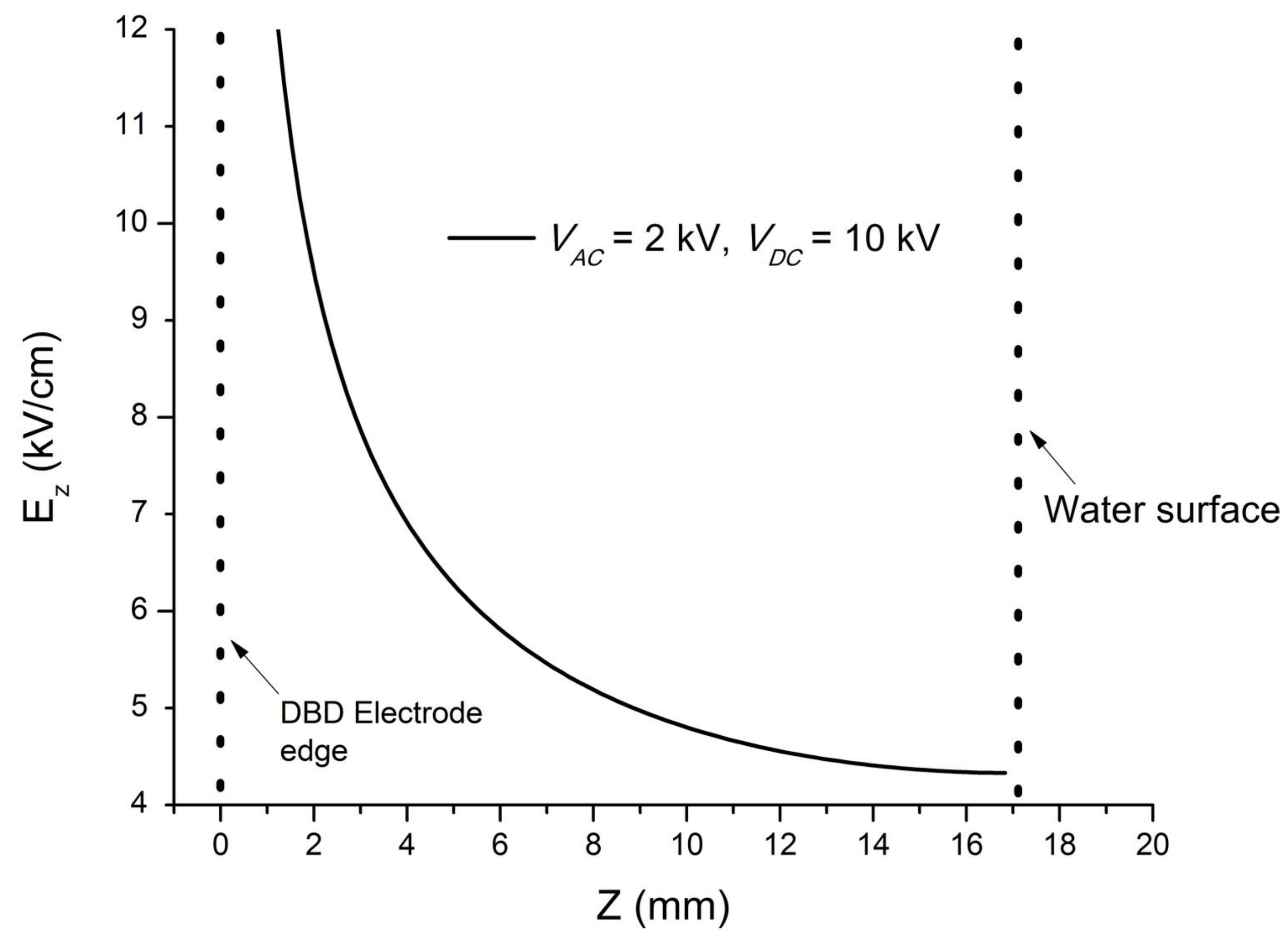




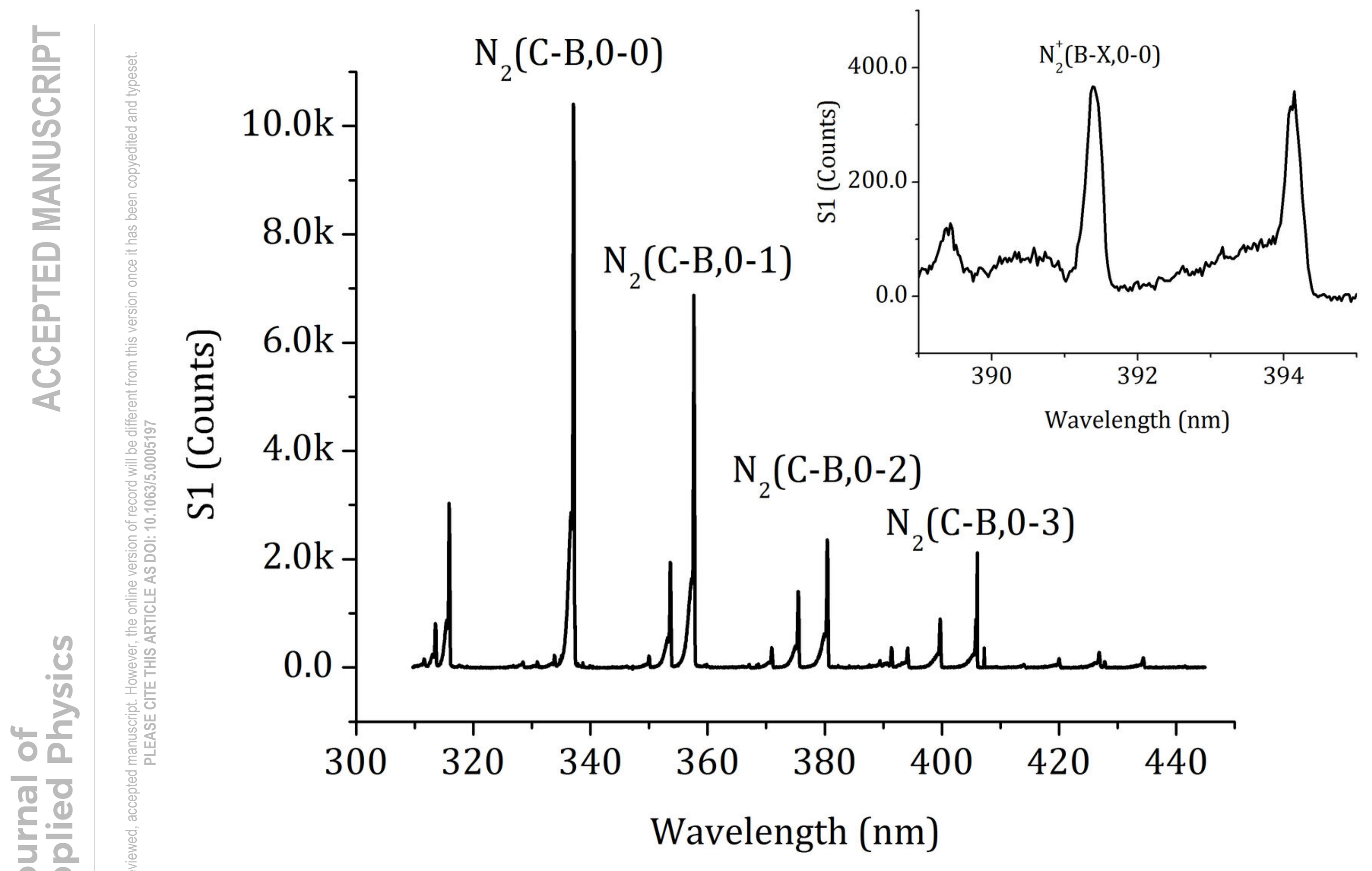




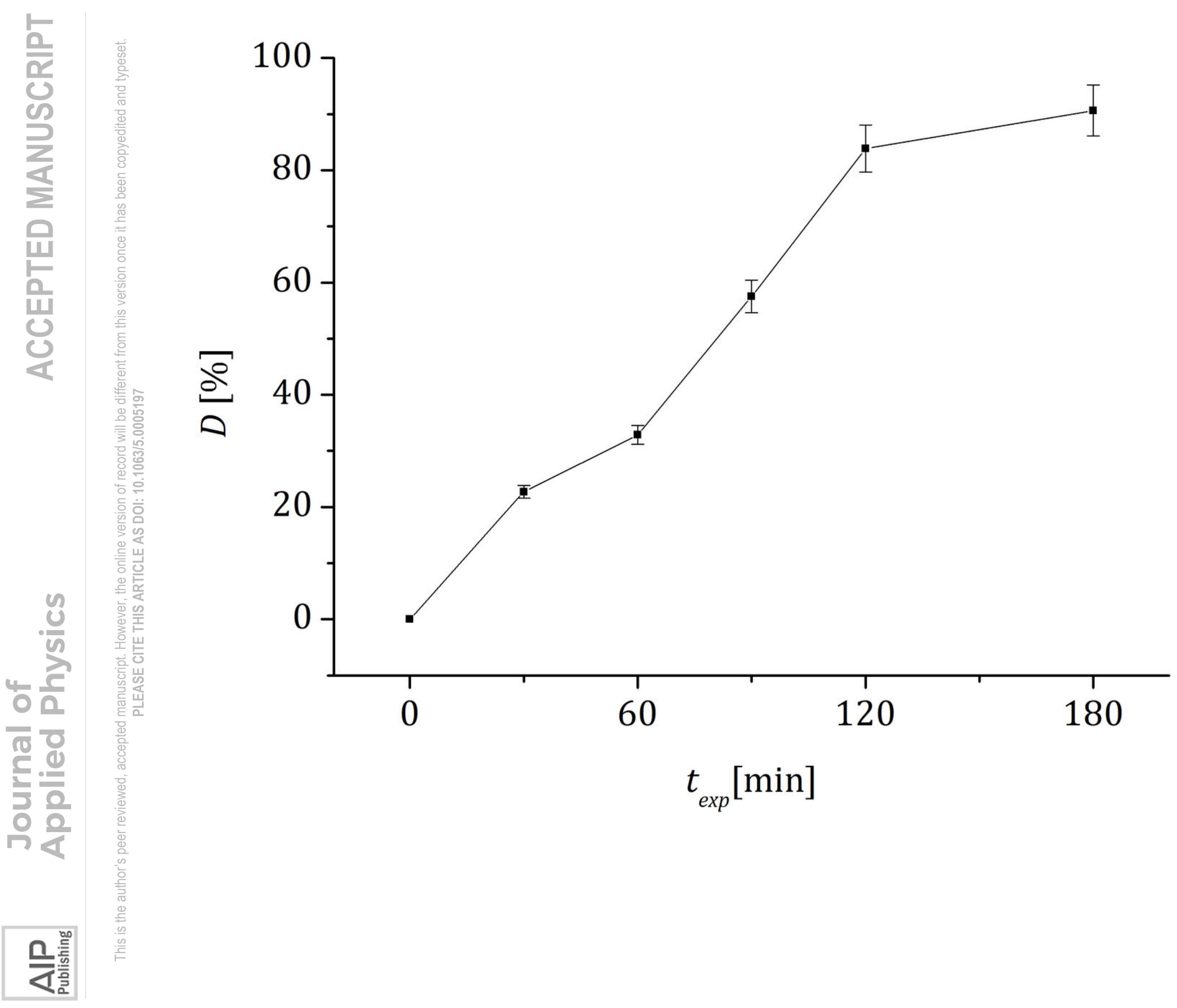




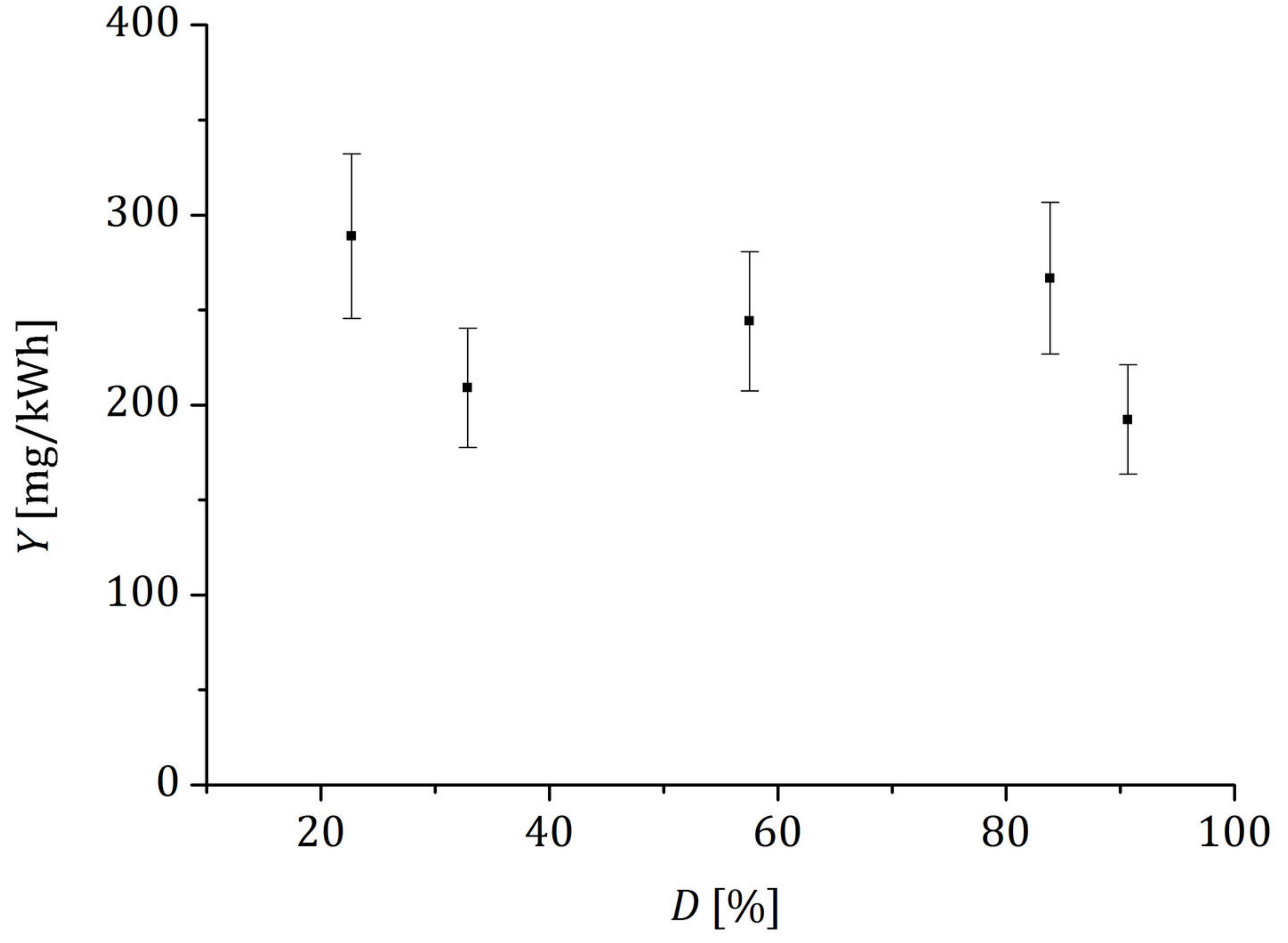

